\title{
Effect of aromatic aldehydes on the electrochemical behavior of bismuth in chloride media
}

\author{
A.G. Berezhnaya ${ }^{1}$ and V.I. Mishurov ${ }^{2}$ \\ ${ }^{1}$ Southern Federal University, Zorge st., 7, Rostov-on-Don, \\ 344090 Russian Federation \\ ${ }^{2}$ Don State Technical University, Gagarin square 1, Rostov-on-Don, \\ 344000 Russian Federation \\ E-mail: ${ }^{1}$ ber@sfedu.ru; ${ }^{2}$ vimishurov@gmail.com
}

\begin{abstract}
The effect of benzaldehyde (I), 2-hydroxy-4-methoxybenzaldehyde (II), 3,4dimethoxybenzaldehyde (III), and $\alpha$-bromocinnamaldehyde (IV) on the partial electrode reactions occurring on bismuth in a neutral chloride solution was investigated. It was established that the dependence of cathodic and anodic process rates on aldehyde concentration is not linear. At equal concentrations, I and III better inhibit cathodic hydrogen evolution than compounds II and IV containing more hydrophilic and hydrophobic substituents, respectively. The aldehydes change the basic parameters of the anodic polarization curve of bismuth. It was shown that dissolution of bismuth in chloride solution with and without the aldehydes studied occurs under diffusion control.
\end{abstract}

Keywords: bismuth, anodic dissolution, activation, passivation, benzaldehyde, 2-hydroxy4-methoxybenzaldehyde, 3,4-dimethoxybenzaldehyde, $\alpha$-bromocinnamaldehyde.

Received: May 10, 2016. Published: June 02, 2016.

doi: $10.17675 / 2305-6894-2016-5-3-2$

\section{Introduction}

The regularities of the effect of various types of organic additives on the anodic behavior of bismuth with consideration for stepwise passivation-activation in neutral chloride media were established previously $[1,2]$. Aromatic aldehydes were not considered as process rate regulators on bismuth but they are known as inhibitors of anodic metal dissolution in neutral media [3,4]. In this paper, the effect of some aromatic aldehydes on the electrochemical behavior of bismuth in $0.1 \mathrm{M}$ sodium chloride solution was studied.

\section{Experimental}

The electrode preparation and experimental technique were described previously [1]. Benzaldehyde (I), 2-hydroxy-4-methoxybenzaldehyde (II), 3,4-dimethoxybenzaldehyde (III), and $\alpha$-bromocinnamaldehyde (IV) were used as additives. Some of them are known as inhibitors of the anodic dissolution of several metals in neutral media. The efficacy of 
additives was estimated by inhibition ratio $\gamma$, which is the ratio of the process rates in a solution with and without an additive.

\section{Results and discussion}

It was shown previously that bismuth undergoes anodic passivation in neutral chloride media, while the alternation of activation and passivation is due to a variation of the film composition [1]. Benzaldehyde (I), 2-hydroxy-4-methoxybenzaldehyde (II), 3,4dimethoxybenzaldehyde (III), and $\alpha$-bromocinnamaldehyde (IV) differ in solubility, which complicates the comparison of their effect on the electrochemical behavior of bismuth. Compound II is well soluble, whereas IV is poorly soluble due to the presence of hydrophilic and hydrophobic substituents, respectively. Aldehydes I and III have approximately the same solubility and occupy an intermediate position. Let us consider the effect of each of the aldehydes mentioned above as a function of their concentration.

Benzaldehyde. Addition of benzaldehyde (I) to the chloride solution decreases the rate of hydrogen reduction and corrosion potential of bismuth, Figure 1, I.
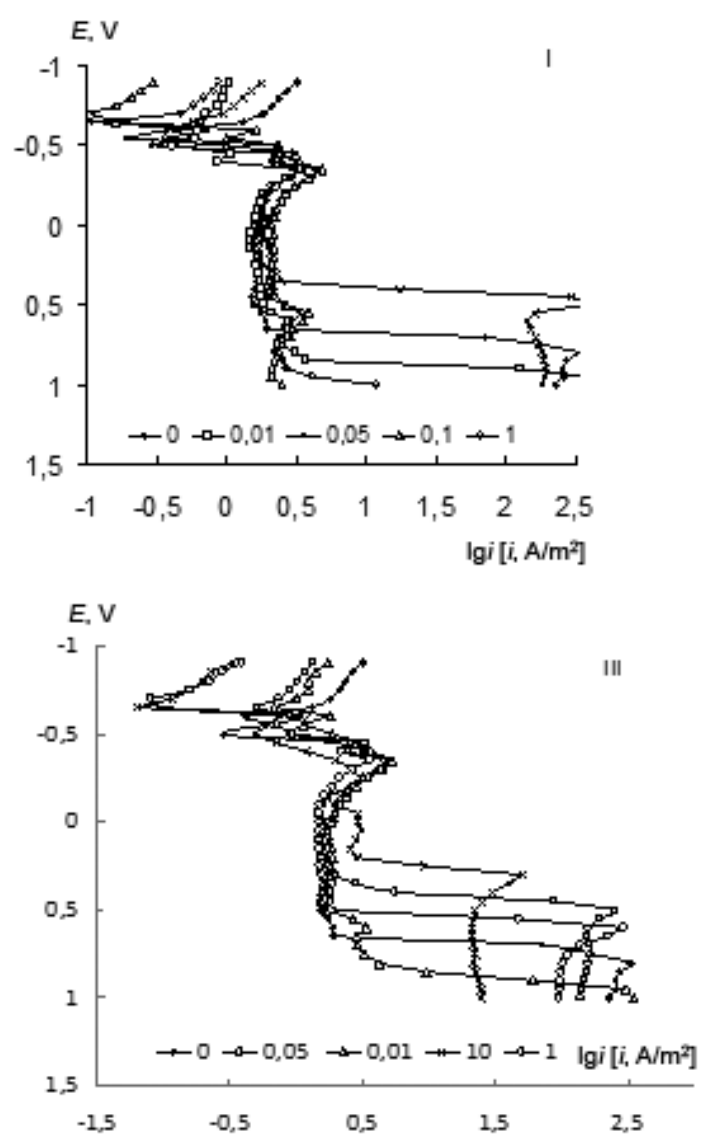
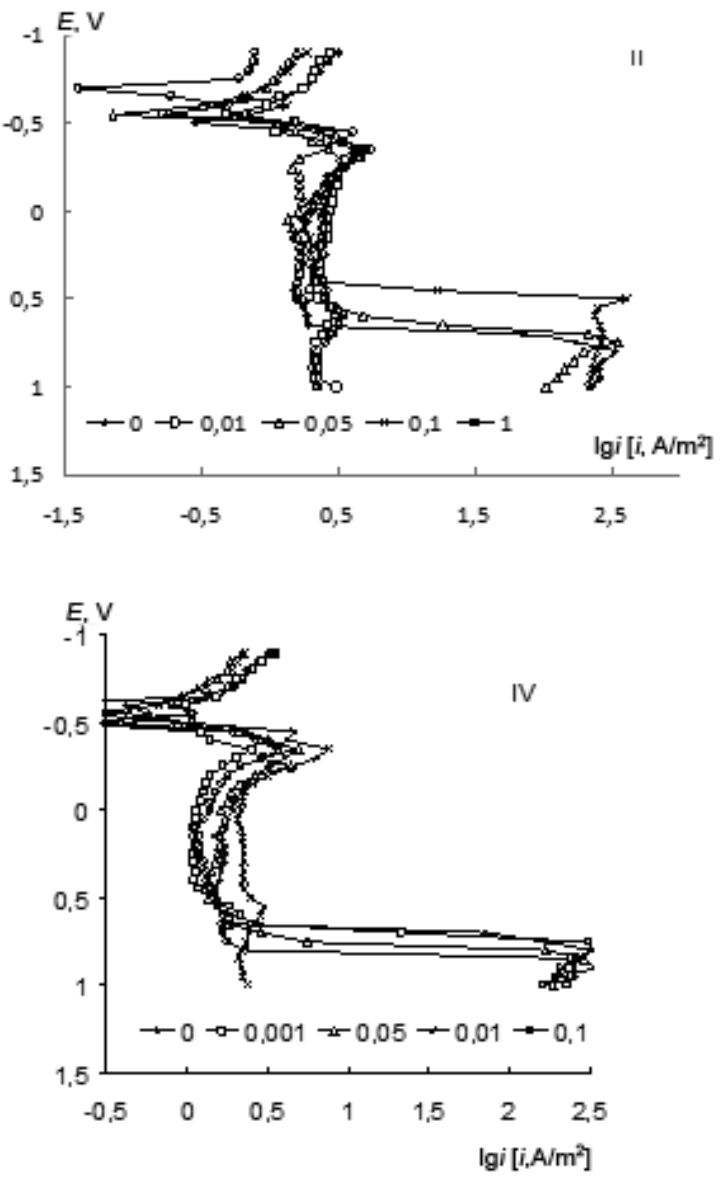

Figure 1. Polarization curves of bismuth in $0.1 \mathrm{M}$ sodium chloride solution $(0)$ and in the presence of aldehydes. Here and below, the numbers in the legend are concentrations, $\mathrm{mmol} / \mathrm{l}$. 
The dependence of the cathodic reaction rate on the concentration of compound $\mathbf{I}$ does not change monotonically. The lowest corrosion rate is observed at $C=0.1 \mathrm{mmol} / 1$. The corrosion potential $E_{\text {cor }}$ decreases by $150 \mathrm{mV}$ at this case, and increases by $50 \mathrm{mV}$ at the lowest concentration of benzaldehyde. The corrosion potential shift in the negative direction leads to apparent stimulation of the anodic process at $E$ close to $E_{\text {cor }}$. All anodic peaks characteristic of bismuth in pure chloride media are observed on its anodic polarization curves in the presence of benzaldehyde. Bismuth(III) oxide is formed at potentials close to $E_{\text {cor. }}$. The anodic peak of bismuth related to the formation of $\mathrm{BiOCl}$ [1] splits into two; the $E$ value of the second peak coincides with the value characteristic of pure $\mathrm{NaCl}$. The first one is observed at lower $E$ values. The current values in the anodic peak and in the range of $E<0.2 \mathrm{~V}$ are lower than in pure chloride at the majority of the concentrations studied. The following dependence exists: the more strongly the additive at some concentration inhibits the cathodic process rate, that is, the more strongly it is adsorbed on the surface, blocks a fraction of it and prevents the formation of an oxide and salt film, the more significantly it stimulates the anodic dissolution of bismuth at $E>0 \mathrm{~V}$, Table 1.

Table 1. Dependence of the process inhibition ratio on the potential and concentration of benzaldehyde.

\begin{tabular}{ccccc}
\hline \multirow{2}{*}{$\begin{array}{c}\text { The range of } \\
\text { potentials or } \boldsymbol{E}, \mathbf{V}\end{array}$} & \multicolumn{4}{c}{$\boldsymbol{\gamma}$ value for concentrations of benzaldehyde, $\mathbf{~ m m o l} / \mathbf{l}$} \\
\cline { 2 - 5 } & $\mathbf{0 . 0 1}$ & $\mathbf{0 . 0 5}$ & $\mathbf{0 . 1}$ & $\mathbf{1}$ \\
\hline-0.9 to -0.7 & 2.5 & 1.80 & 11.5 & 3.61 \\
-0.65 & 1.99 & 2.34 & 8.22 & 12.2 \\
-0.6 & 0.68 & 1.14 & 0.25 & 0.58 \\
-0.55 & 1.0 & 1.0 & 0.59 & 1.63 \\
-0.5 & 0.71 & 0.29 & 0.12 & 0.12 \\
-0.45 to 0 & 1.42 & 1.0 & 0.97 & 1.33 \\
0.05 to 0.35 & 1.0 & 1.0 & 0.81 & 0.82 \\
0.4 to 0.65 & 0.84 & 0.01 & 0.56 & 0.58 \\
0.7 & 74.6 & 1.0 & 71.2 & 74.0 \\
0.8 & 108.7 & 1.83 & 141.2 & 153.1 \\
0.9 & 2.02 & 1.33 & 121.8 & 96.2 \\
1.0 & 0.61 & 1.23 & 90.2 & 19.1 \\
\hline
\end{tabular}

The third anodic peak, which results from the formation of one of basic bismuth salts [1], is observed at $C=0.05 \mathrm{mmol} / 1$ at a potential $300 \mathrm{mV}$ lower than $E_{\mathrm{ap}, 3}$ in pure chloride solution. The current stabilizes at $E=0.55 \mathrm{~V}$ where its values are higher by two orders than the current in the passive state. At the other $C_{\mathbf{I}}$ values, the third peak is observed at 
higher $E$. This leads to a substantial increase in the inhibition ratio that is close to or higher than 100 , Table 1 .

The concentration dependences of the process rate are not linear in various sections of the curve, and at higher potentials the curve with a maximum is observed at $C=$ $0.05 \mathrm{mmol} / \mathrm{l}$.

2-Hydroxy-4-methoxybenzaldehyde decreases the cathodic reaction rate and $E_{\text {cor }}$ less strongly than benzaldehyde, but monotonically with an increase in concentration, Figure 1, Table 2.

Table 2. Some characteristics of polarization curves of bismuth in sodium chloride solution in the absence $(0)$ and in the presence of 2-hydroxy-4-methoxybenzaldehyde.

\begin{tabular}{|c|c|c|c|c|c|}
\hline \multirow{2}{*}{ Parameter } & \multicolumn{5}{|c|}{ Parameter value depending on $C_{\mathrm{II}}, \mathrm{mmol} / \mathrm{l}$} \\
\hline & $\mathbf{0}$ & 0.01 & 0.05 & 0.1 & 1 \\
\hline$i_{E}=-0.9 \mathrm{~V}, \mathrm{~A} / \mathrm{m}^{2}$ & 3.16 & 2.74 & 1.87 & 1.56 & 0.79 \\
\hline$E_{\text {cor }}, \mathrm{V}$ & -0.55 & -0.55 & -0.625 & -0.625 & -0.625 \\
\hline$E_{\mathrm{ap}, 1}, \mathrm{~V}$ & -0.55 & -0.5 & -0.6 & -0.6 & -0.60 \\
\hline$i_{\mathrm{ap}, 1}, \mathrm{~A} / \mathrm{m}^{2}$ & 0.84 & 1.50 & 0.32 & 1.33 & 0.49 \\
\hline$E_{\mathrm{ap}, 2}, \mathrm{~V}$ & -0.35 & -0.35 & -0.35 & -0.35 & -0.35 \\
\hline$i_{\mathrm{ap}, 2}, \mathrm{~A} / \mathrm{m}^{2}$ & 4.82 & 4.28 & 4.18 & 4.17 & 5.46 \\
\hline$E_{\mathrm{ap}, 3}, \mathrm{~V}$ & 0.8 & 0.6 & 0.75 & 0.5 & 0.6 \\
\hline$i_{\mathrm{ap}, 3}, \mathrm{~A} / \mathrm{m}^{2}$ & 332.8 & 3.4 & 352.7 & 255.7 & 3.5 \\
\hline$i_{E=0.9 \mathrm{~V}}, \mathrm{~A} / \mathrm{m}^{2}$ & 254.0 & 2.3 & 227.3 & 227.7 & 2.1 \\
\hline
\end{tabular}

Additive II has virtually no effect on the cathodic hydrogen evolution rate and active dissolution of bismuth at the smallest $C=0.01 \mathrm{mmol} / \mathrm{l}$; it increases the rate of full passivation and inhibits the third anodic peak. Compound II has a similar effect on the anodic reaction at the highest $C$, but it also inhibits substantially the cathodic hydrogen evolution and decreases the corrosion potential by $100 \mathrm{mV}$. At intermediate concentrations, the additive inhibits both electrode reactions and favors the occurrence of $E_{\mathrm{ap}, 3}$.

3,4-Dimethoxybenzaldehyde. Introduction of two methoxy groups into the benzene ring compared with benzaldehyde or substitution of hydrophilic hydroxy group at position 2 by a methoxy group at position 3 in comparison with 2-hydroxy-4-methoxybenzaldehyde results in a change of the shape of bismuth polarization curves. Compound III decreases $E_{\text {cor }}$ and significantly reduces the cathodic hydrogen evolution rate with an increase in concentration, Table 3. 
Table 3. Some characteristics of polarization curves of bismuth in sodium chloride solution in the absence (0) and in the presence of 3,4-dimethoxybenzaldehyde.

\begin{tabular}{cccccc}
\hline \multirow{2}{*}{ Parameter } & \multicolumn{5}{c}{ Parameter value depending on $\boldsymbol{C}_{\text {III }}, \mathbf{m m o l} / \mathbf{l}$} \\
\cline { 2 - 5 } & $\mathbf{0}$ & $\mathbf{0 . 0 1}$ & $\mathbf{0 . 0 5}$ & $\mathbf{1}$ & $\mathbf{1 0}$ \\
\hline$i_{E=-0.9 \mathrm{~V}, \mathrm{~A} / \mathrm{m}^{2}}$ & 3.16 & 1.74 & 1.32 & 0.38 & 0.33 \\
$E_{\mathrm{cor}}, \mathrm{V}$ & -0.55 & -0.625 & -0.625 & -0.675 & -0.625 \\
$E_{\mathrm{ap}, 1}, \mathrm{~V}$ & -0.55 & -0.60 & -0.55 & -0.60 & -0.60 \\
$i_{\mathrm{ap}, 1}, \mathrm{~A} / \mathrm{m}^{2}$ & 0.84 & 1.8 & 1.16 & 0.17 & 0.75 \\
$E_{\mathrm{ap}, 2}, \mathrm{~V}$ & -0.35 & -0.35 & -0.35 & -0.45 & -0.25 \\
$i_{\mathrm{ap}, 2}, \mathrm{~A} / \mathrm{m}^{2}$ & 4.82 & 5.23 & 4.62 & 3.31 & 3.08 \\
$E_{\mathrm{ap}, 3}, \mathrm{~V}$ & 0.8 & 0.95 & 0.5 & 0.6 & 0.3 \\
$i_{\mathrm{ap}, 3}, \mathrm{~A} / \mathrm{m}^{2}$ & 332.8 & 305.7 & 249.1 & 296.3 & 51.7 \\
$i_{E=0.9 \mathrm{~V}, \mathrm{~A} / \mathrm{m}^{2}}$ & 254.0 & 60.2 & 147.2 & 97.5 & 23.5 \\
\hline
\end{tabular}

Compound III accelerates the process at potentials close to $E_{\text {ap }, 1}(E=-0.6$ to $-0.5 \mathrm{~V})$. At higher potentials, inhibition or nearly absence of any effect on the anodic process is observed at the majority of concentrations $C$ studied (except $C=0.1 \mathrm{mmol} / \mathrm{l}$ ) up to $E=$ $0.3 \mathrm{~V}$, Figure 1, Table 4.

Table 4. The dependence of the process inhibition ratio on the potential and concentration of 3,4dimethoxybenzaldehyde.

\begin{tabular}{ccccc}
\hline $\begin{array}{c}\text { The range of } \\
\text { potentials or } \boldsymbol{E}, \mathbf{V}\end{array}$ & \multicolumn{4}{c}{$\boldsymbol{\gamma}$ value for concentrations of $\boldsymbol{C}_{\mathbf{I I I}}, \mathbf{m m o l} / \mathbf{l}$} \\
\cline { 2 - 5 } & $\mathbf{0 . 0 1}$ & $\mathbf{0 . 0 5}$ & $\mathbf{0 . 1}$ & $\mathbf{1}$ \\
\hline-0.9 to -0.7 & 1.82 & 2.37 & 12.95 & 12.51 \\
-0.65 & 1.92 & 2.57 & 15.64 & 20.56 \\
-0.6 & 0.23 & 0.46 & 0.35 & 0.55 \\
-0.55 & 0.16 & 0.32 & 0.31 & 0.60 \\
-0.5 & 0.17 & 0.31 & 0.30 & 0.58 \\
-0.45 to 0 & 0.98 & 1.23 & 1.48 & 1.32 \\
0.05 to 0.45 & 0.94 & 1.05 & 1.12 & 0.58 \\
0.5 to 0.65 & 0.63 & 0.01 & 0.03 & 0.08 \\
0.7 & 24.2 & 0.43 & 0.53 & 3.27 \\
0.8 & 79.78 & 2.31 & 3.25 & 15.31 \\
0.9 & 1.72 & 4.22 & 2.61 & 10.81 \\
1.0 & 0.65 & 1.61 & 2.33 & 8.89 \\
\hline
\end{tabular}


Compound III decreases $E_{\mathrm{ap}, 3}$ and promotes the formation of a basic bismuth salt practically at all concentrations.

$\alpha$-Bromocinnamaldehyde differs in its effect from benzaldehyde. It is characterized by lower solubility and has an inhibitory effect on the cathodic hydrogen evolution rate at $C=0.01-0.05 \mathrm{mmol} / \mathrm{l} . \alpha$-Bromocinnamaldehyde weakly stimulates the cathodic hydrogen evolution at the highest $C$, Figure 1, Table 5 .

Table 5. Some characteristics of polarization curves of bismuth in sodium chloride solution in the absence $(0)$ and in the presence of $\alpha$-bromocinnamaldehyde.

\begin{tabular}{cccccc}
\hline \multirow{2}{*}{ Parameter } & \multicolumn{5}{c}{ Parameter value depending on $\boldsymbol{C}_{\mathbf{I V}}, \mathbf{m m o l} / \mathbf{l}$} \\
\cline { 2 - 5 } & $\mathbf{0}$ & $\mathbf{0 . 0 0 1}$ & $\mathbf{0 . 0 1}$ & $\mathbf{0 . 0 5}$ & $\mathbf{0 . 1}$ \\
\hline$i_{E=-0.9 \mathrm{~V}, \mathrm{~A} / \mathrm{m}^{2}}$ & 3.16 & 3.16 & 2.30 & 2.18 & 3.42 \\
$E_{\mathrm{cor}}, \mathrm{V}$ & -0.55 & -0.525 & -0.525 & -0.55 & -0.55 \\
$E_{\mathrm{ap}, 1}, \mathrm{~V}$ & -0.55 & - & - & - & -0.525 \\
$i_{\mathrm{ap}, 1}, \mathrm{~A} / \mathrm{m}^{2}$ & 0.83 & - & - & - & 1.1 \\
$E_{\mathrm{ap}, 2}, \mathrm{~V}$ & -0.35 & -0.35 & -0.35 & -0.35 & -0.35 \\
$i_{\mathrm{ap}, 2}, \mathrm{~A} / \mathrm{m}^{2}$ & 4.82 & 2.53 & 7.64 & 4.94 & 3.71 \\
$E_{\mathrm{ap}, 3}, \mathrm{~V}$ & 0.8 & 0.8 & 0.55 & 0.90 & 0.85 \\
$i_{\mathrm{ap}, 3}, \mathrm{~A} / \mathrm{m}^{2}$ & 332.8 & 334.0 & 2.98 & 342.0 & 262.7 \\
$i_{E=0.9 \mathrm{~V}, \mathrm{~A} / \mathrm{m}^{2}}$ & 254.0 & 236.9 & 2.2 & 342.0 & 208.6 \\
\hline
\end{tabular}

Compound IV does not change the corrosion potential but inhibits the first anodic peak. It decreases the anodic process rate and increases the potential of the third anodic peak at the highest concentration at all investigated $E$. The process rate decreases with a further potential increase in the presence of the additive in comparison with a solution containing no additive.

It should be noted that at the lowest concentration, IV has practically no effect on the cathodic reaction rate, but it better inhibits the anodic reaction, both at potentials of the second anodic peak and in the steady passive state, and has no effect on $E_{\mathrm{ap}, 3}$.

The inhibition ratios depending on $E$ and the concentration of the additive are presented in Table 6. 
Table 6. The dependence of the process inhibition ratio on the potential and concentration of $\alpha$ bromocinnamaldehyde.

\begin{tabular}{ccccc}
\hline \multirow{2}{*}{$\begin{array}{c}\text { The range of } \\
\text { potentials or } \boldsymbol{E}, \mathbf{V}\end{array}$} & \multicolumn{4}{c}{$\boldsymbol{\gamma}$ value for concentrations of $\boldsymbol{C}_{\mathbf{I V}}, \mathbf{m m o l} / \mathbf{l}$} \\
\cline { 2 - 5 } & $\mathbf{0 . 0 0 1}$ & $\mathbf{0 . 0 1}$ & $\mathbf{0 . 0 5}$ & $\mathbf{0 . 1}$ \\
\hline-0.9 to -0.7 & 0.90 & 1.29 & 1.35 & 0.91 \\
-0.65 & 0.86 & 1.51 & 1.36 & 0.86 \\
-0.6 & 0.41 & 0.46 & 0.35 & 0.55 \\
-0.55 & 0.54 & 0.62 & 4.31 & 0.51 \\
-0.5 & 1.37 & 0.27 & 0.33 & 0.72 \\
-0.45 to 0 & 1.98 & 0.75 & 1.00 & 1.34 \\
0.05 to 0.45 & 1.54 & 0.76 & 1.12 & 1.35 \\
0.5 to 0.65 & 0.95 & 0.71 & 1.13 & 1.18 \\
0.7 & 3.28 & 28.43 & 24.53 & 43.27 \\
0.8 & 1.00 & 154.31 & 1.95 & 143.31 \\
0.9 & 1.07 & 116.22 & 0.74 & 1.21 \\
1.0 & 0.99 & 94.61 & 1.23 & 1.38 \\
\hline
\end{tabular}

The dependence of cathodic and anodic reaction rates on the concentration of IV is not linear. It has a V-or $\Lambda$-shape depending on the process. A more distinct $\mathrm{V}$-shape is observed at high potentials because the rates concerned correspond to different processes.

Effect of aldehydes on the bismuth dissolution mechanism in neutral chloride media. The chronoamperograms of bismuth recorded at $E=0.1 \mathrm{~V}$ in the pure chloride solution and in the presence of aldehydes have a similar form. The dissolution of bismuth in the pure chloride solution and in the presence of all the aldehydes studied occurs under diffusion control, often with an induction period, irrespective of the time range considered. The induction period is due to phase processes associated with formation and compacting of a passivating film.

The character of aldehyde influence on the process rate and its variation with time is determined by the nature of the aldehyde. The ratio of process inhibition changes with time, Figure 3.

Thus, 2-hydroxy-4-methoxybenzaldehyde is the most effective inhibitor at $E=0.1 \mathrm{~V}$. The inhibition ratio in its presence increases with time throughout the sample exposure. The tendency to a constant $\gamma$ value is realized in the remaining aldehydes; it is worth noting that benzaldehyde is a weak stimulator under these conditions. 

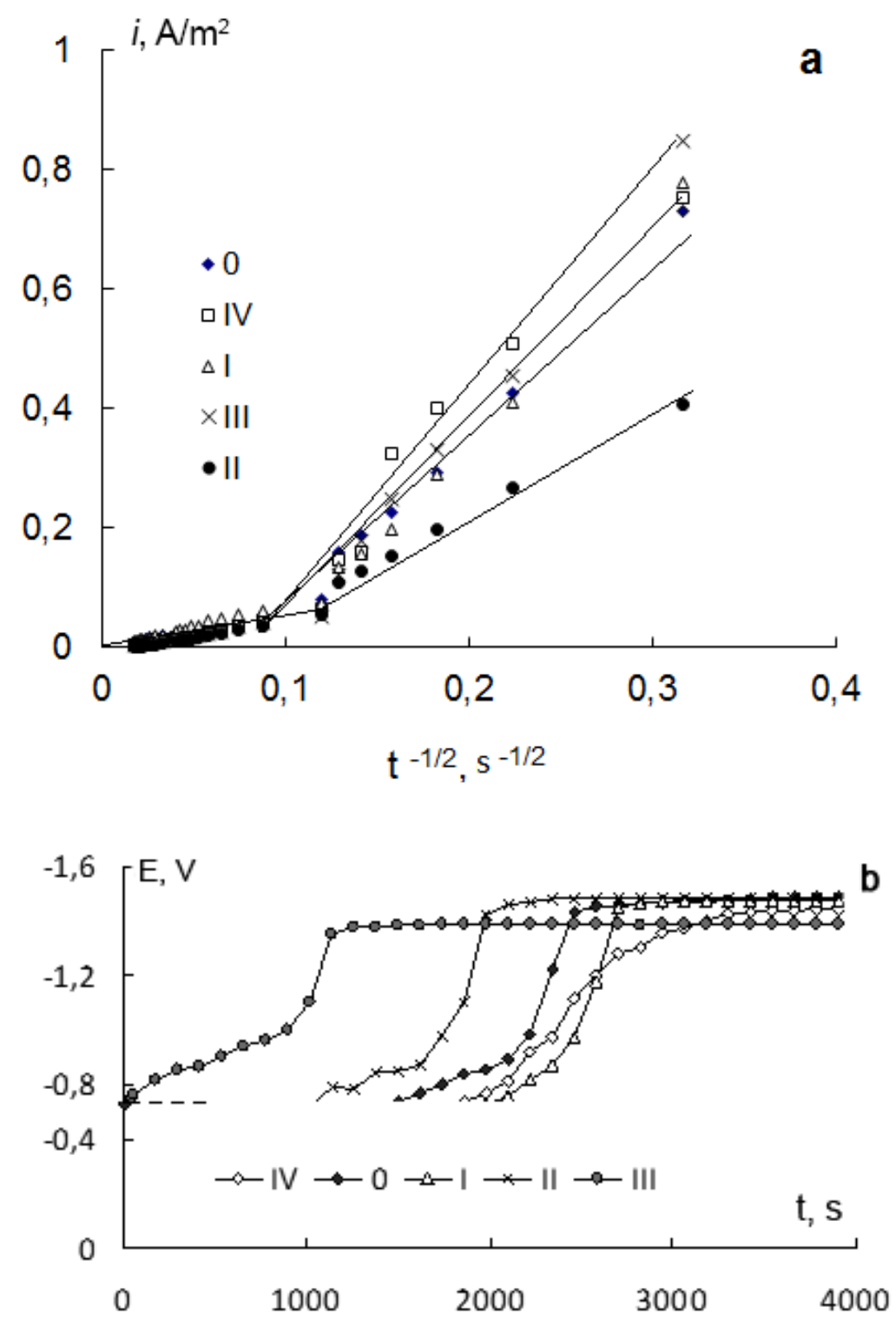

Figure 2. Chronoamperograms $(a)$ and chronopotentiograms $(b)$ of bismuth obtained in neutral chloride solution ( 0 ) and in the presence of aldehydes $(\mathbf{I}-\mathbf{I V}) . E=0.1 \mathrm{~V}, i_{\mathrm{c}}=10 \mathrm{~A} / \mathrm{m}^{2}$, $C=0.1 \mathrm{mmol} / \mathrm{l}$.

Potential delays were obtained on the cathodic chronopotentiograms taken immediately after recording the amperograms. They are caused by reduction of the products of bismuth anodic dissolution and are observed at about $E=-0.6$ to $-0.7 \mathrm{~V}$, except for with 2-hydroxy-4-methoxybenzaldehyde, for which the potential and its delay time are significantly smaller, Figure 2. 


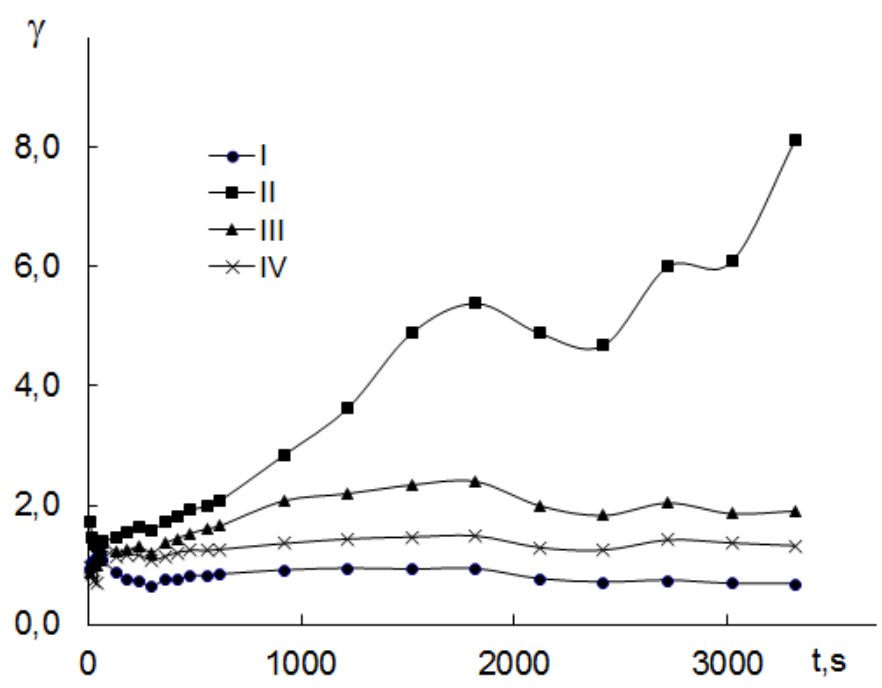

Figure 3. Plots of inhibition ratio $v s$. time.

\section{Conclusions}

Bismuth is anodically passivated in neutral chloride media due to the formation of $\mathrm{Bi}_{2} \mathrm{O}_{3}$, $\mathrm{BiOCl}$ and a salt film on the surface. The aromatic aldehydes studied are inhibitors of cathodic hydrogen evolution. They facilitate passivation and promote the formation of a basic bismuth salt. The concentration dependences of cathodic and anodic reactions rates are not linear. Bismuth dissolves under diffusion control both in the pure chloride solution and in a presence of the aldehydes.

\section{References}

1. V.V. Ekilik, E.A. Korsakova, A.G. Berezhnaya and E.I. Momotova, Korroz.: mater., zashch., 2012, no. 12, 1 (in Russian).

2. V.V. Ekilik, E.A. Korsakova, A.G. Berezhnaya and E.I. Momotova, Korroz.: mater., zashch., 2013, no. 11, 21 (in Russian).

3. V.V. Ekilik, A.G. Berezhnaya and E.A. Tugolukova, Izvestiya VUZov. Sev.-Kav. region. Tech. nauki, 2004, Special Issue, 21 (in Russian).

4. V.V. Ekilik, A.G. Berezhnaya and E.A. Tugolukova, Korroz.: mater., zashch., 2004, no. 5, 32 (in Russian). 